JURNAL ILMIAH KEBIDANAN IMELDA

Vol.6, No.2, September 2020, pp. 77-83

ISSN: 2597-7180 (Online),2442-8116 (Print)

\title{
GAMBARAN PENGETAHUAN IBU TENTANG PENTINGNYA INISIASI MENYUSUI DINI (IMD) PADA BAYI BARU LAHIR DI DESA CINTA RAKYAT TAHUN 2020
}

\author{
Mira Indrayani \\ Universitas Imelda Medan, Indonesia
}

\begin{tabular}{l}
\hline Article Info \\
\hline Article history: \\
Received Sep 26, 2019 \\
Revised Sep 28, 2020 \\
Accepted Sep 29, 2020 \\
\hline
\end{tabular}

Keywords:

Knowledge

Early Initiation of Breastfeeding

Newborns

\begin{abstract}
Child mortality in Indonesia is often found in neonatal age or young infants with a ratio of 19 per 1000 children who die in the age range of 0 days- 2 months. In an effort to increase the life expectancy of children, WHO has created a newborn health guide that recommends various care for maintaining the health of newborns and the management of handling sick babies In Indonesia, this has also been stated in the regulation of the minister of health regarding integrated management of young infants, known as MTBM. One of the core interventions that is an indicator of the success of child survival, namely early breastfeeding as part of essential care for newborns. The purpose of this study was to determine the description of mother's knowledge about the importance of IMD in newborns in The Village Of People's Love. This research is descriptive in nature using primary data where the data is taken directly from the respondents using a closed questionnaire sheet totaling 20 questions. The time of this research was started from June-July 2020. The research location was conducted in The Village Of People's Love. The population in this study amounted to 30 people. The sampling technique used "total sampling" with 30 respondents. Based on the research conducted, 14 respondents (46.67\%) had sufficient knowledge and $6(20 \%)$ had good knowledge. For health workers, it is expected to increase education to mothers about the importance of Early Initiation of Breastfeeding for Newborns.
\end{abstract}

This is an open access article under the CC BY-SAlicense.

This is an open access article under the CC BY-SAlicense.
Corresponding Author:
Mira Indrayani,
Program Studi S1 Kebidanan,
Universitas Imelda Medan,
J1. Bilal No. 52 Kelurahan Pulo Brayan Darat I Kecamatan Medan Timur, Medan - Sumatera Utara.
Email: miraindrayani19@gmail.com

\section{INTRODUCTION}

Inisiasi menyusui dini adalah suatu prosedur langkah awal yang harus dilakukan antara ibu dan bayi. Inisiasi menyusu dini dilakukan dengan cara membiarkan ibu melekat pada kulit bayi (skin to skin) segera setelah persalinan. Kontak kulit ini di biarkan setidaknya selama satu jam atau sampai menyusui awal sekali. (Ria Riksani, 2010).

Kematian anak di Indonesia sering dijumpai pada usia neonatal atau bayi muda dengan rasio 19 per 1000 anak yang meninggal pada rentang usia 0 hari-2 bulan. Sebagai upaya untuk meningkatkan angka harapan hidup anak, WHO telah membuat panduan kesehatan bayi baru lahir yang merekomendasikan berbagai asuhan untuk menjaga kesehatan bayi baru lahir serta manajemen penanganan bayi sakit. Di 
Indonesia, hal tersebut juga telah tercantum dalam peraturan menteri kesehatan mengenai manajemen terpadu bayi muda atau yang dikenal dengan MTBM. Salah satu intervensi inti yang menjadi indikator keberhasilan kelangsungan hidup anak yaitu iniasi menyusu dini sebagai bagian dalam perawatan esensial bayi baru lahir (Kanal Pengetahuan FK UGM, 2017).

Upaya pemeliharaan kesehatan anak ditujukan untuk mempersiapkan generasi akan datang yang sehat, cerdas, dan berkualitas serta untuk menurunkan angka kematian anak. Indikator angka kematian yang berhubungan dengan anak yakni Angka Kematian Neonatal (AKN), Angka Kematian Bayi (AKB), dan Angka Kematian Balita (AKABA). Angka kematian anak dari tahun ke tahun menunjukkan penurunan. Hasil Survei Demografi dan Kesehatan Indonesia (SDKI) tahun 2017 menunjukkan AKN sebesar 15 per 1.000 kelahiran hidup, AKB 24 per 1.000 kelahiran hidup, dan AKABA 32 per 1.000 kelahiran hidup (Profil Kesehatan Indonesia, 2017).

Inisiasi Menyusui Dini sesungguhnya merupakan gerbang awal dalam kesuksesan pemberian ASI eksklusif pada bayi. Berdasarkan penelitian, Angka kematian pada bayi pun menurun secara signifikan pada bayi yang mendapatkan ASI eksklusif pada 1 jam pertama kehidupannya. Hal ini tentu saja tidak terlepas dari kolostrum yang di dapatkan bayi pada hari-hari pertama sejak kelahiran yang akan melindunginya dari berbagai penyakit dan infeksi. Dengan demikian, Inisiasi Menyusui Dini akan menurunkan angka kesakitan dan kematian pada bayi baru lahir. (Ria Riksani, 2010).

Angka kematian bayi diseluruh dunia saat ini setiap tahunnya mencapai 4 juta jiwa. Di indonesia saat ini tercatat angka kematian bayi masih sangat tinggi yaitu 35 tiap 1000 kelahiran hidup pada tahun 2008, yang artinya dalam satu tahun sekitar 175.000 bayi meninggal sebelum mencapai usia satu tahun penyebab kematian bayi di karenakan beberapa faktor yaitu salah satunya kurang nya pengetahuan tentang Inisiasi Menyusui Dini dan pemberian ASI Eksklusif (Sutiyah, 2010).

Setiap bayi baru lahir berhak mendapatkan air susu ibunya, karena dengan pemberian Air Susu Ibu (ASI) dalam satu jam pertama kehidupannya, maka bayi akan mendapat sumber gizi terbaik dan dapat menyelamatkan jiwa bayi pada bulan-bulan pertama yang rawan. Hal ini mengingat masih tingginya angka kematian bayi baru lahir.

Di Indonesia saat ini tercatat angka kematian bayi masih sangat tinggi yaitu 35 tiap 1.000 kelahiran hidup pada tahun 2008, yang artinya dalam satu tahun sekitar 175.000 bayi meninggal sebelum mencapai usia satu tahun. Angka kematian bayi di Indonesia menurut Survei Demografi dan Kesehatan Indonesia (SDKI) 2002-2003 masih sangat tinggi yaitu 35 per 1.000 kelahiran hidup. Berdasarkan data SDKI tahun 1997 dan 2002 lebih dari 95\% ibu pernah menyusui bayinya, namun yang menyusui dalam 1 jam pertama cenderung menurun dari 8\% pada tahun 1997 menjadi 3,7\% pada tahun 2002 (Salamah, 2006).

Di Sumatra Utara, Angka kematian ibu dan bayi masih lebih tinggi di bandingkan dengan nilai ratarata nasional. Berdasarkan data tahun 2007 rata-rata angka kematian Ibu di Sumatra Utara 330 per 100.000 kelahiran hidup, sedangkan angka kematian bayi sekitar 37 per 1000 kelahiran hidup (Siswono, 2008).

Ibu bisa membiarkan bayinya belajar menyusu sendiri begitu bayi dilahirkan. Keberhasilan IMD ini telah di buktikan dengan penelitian yang dilakukan terhadap bayi 10.947 bayi baru lahir antara bulan Juli 2003 dan juni 2004 di Ghana, ternyata bila bayi dapat menyusu 1 jam pertama dapat menyelamatkan 22\% bayi dari kematian saat bayi baru lahir (Anik Maryunani, 2009 hal 56).

Salah satu alasan pentingnya Inisiasi Menyusui Dini (IMD) untuk menyesuaikan suhu ideal yang di perlukan bayi yaitu dapat turun 10 derajat dan naik sampai 20 derajat Celsius, sehingga dapat menurunkan kematian bayi akibat kedinginan (Anik Maryunani 2009 hal 57).

Menurut Aprilia pada penelitianya di RSUD. Prof. Dr. H. Aloei Saboe bahwa masih banyak terdapat ibu-ibu yang tidak mau dilakukan IMD tersebut dengan berbagai alasan misalnya, bayi akan kedinginan, ibu merasa kelelahan, dan ASI yang di keluarkan merupakan ASI yang tidak baik untuk bayi, ada juga ibu yang mengatakan kalau mereka harus melakukan rangsangan atau perawatan payudara terlebih dahulu setelah itu ASI baru dapat keluar. Untuk menambah pengetahuan ibu tentang pentingnya IMD ada proses persalinan dan menyusui, salah satu untuk meningkatkan termotivasinya melakukan Inisiasi Menyusui dini adalah bidan atau pun perawat harus berupaya memberikan penyuluan kesehatan kepada ibu tentang pentingnya IMD (Aprillia, 2009).

Dari uraian diatas bahwa Inisiasi menyusui dini sangat penting dilakukan karena akan menekan angka kematian pada bayi baru lahir, sehingga peneliti tertarik untuk melakukan penelitian yang berjudul "Gambaran Pengetahuan Ibu tentang pentingnya Inisiasi Menyusui Dini (IMD) pada Bayi Baru Lahir Di wilayah kerja Di Desa Cinta Rakyat.

Berdasarkan Latar Belakang diatas maka penulis berkeinginan untuk melakukan penelitian dan merumuskan masalah yang berjudul "Gambaran Pengetahuan Ibu tentang pentingnya IMD pada Bayi Baru Lahir di Di wilayah kerja Di Desa Cinta Rakyat. Tujuan dilakukannya penelitian ini adalah untuk mengetahui Gambaran Pengetahuan Ibu tentang pentingnya IMD pada Bayi Baru Lahir di wilayah kerja Di Desa Cinta Rakyat. 
1. Untuk mengetahui gambaran pengetahuan ibu tentang penting nya IMD pada bayi baru lahir Diwilayah kerja Desa Cinta Rakyat

2. Untuk mengetahui gambaran pengetahuan ibu tentang penting nya IMD pada bayi baru lahir Diwilayah kerja Desa Cinta Rakyatberdasarkan paritas

3. Untuk mengetahui gambaran pengetahuan ibu tentang penting nya IMD pada bayi baru lahir Diwilayah kerja Desa Cinta Rakyatberdasarkan sumber informasi

\section{RESEARCH METHOD}

Penelitian ini bersifat deskriptif untuk mengetahui sejauh mana Gambaran Pengetahuan Ibu tentang pentingnya IMD pada Bayi Baru Lahir. Penelitian ini menggunakan data primer yang didapat langsung dari responden dengan menggunakan kuesioner (Notoadmojo, 2010). Lokasi penelitian ini adalah di Di Wilayah Kerja Desa Cinta Rakyat. Instrumen penelitian adalah alat yang akan di gunakan untuk mengumpulkan data. Instumen penelitian ini menggunakan kuesioner sebanyak 20 pertanyaan yang akan di bagi pada responden.

Populasi adalah totalitas semua nilai yang mungkin, baik hasil menghitung maupun pengukuran kuantitatif ataupun kualitatif dari pada karakteristik tertentu mengenai sekumpulan objek yang lengkap dan jelas (Sudjana, 2005). Populasi penelitian adalah keseluruhan objek penelitian atau objek yang di teliti (Notoatmodjo, 2010 ). Populasi yang diambil dari pada penelitian ini adalah seluruh ibu hamil yang datang berkunjung di Di wilayah kerja Desa Cinta Rakyat.

Sampel adalah sebagian yang diambil dari populasi dengan menggunakan cara-cara tertentu. (Sudjana, 2005). Sampel penelitian adalah objek yang di teliti dan di anggap mewakili seluruh populasi (Notoadmodjo, 2010). Adapun kriteria sampel yang di gunakan yaitu kriteria inklusi yaitu kriteria atau ciri - ciri yang perlu dipenuhi oleh setiap anggota populasi yang dapat di ambil sebagai sampel (Notoatmodjo, 2010). Pengambilan sampel pada penelitian ini adalah secara total sampling dengan jumlah sampel 30 responden.

\section{Metode Pengumpulan Data}

Penelitian ini menggunakan data primer yang di dapat melalui kuesioner tertutup yang di buat sendiri oleh peneliti berdasarkan konsep yang terdiri dari 20 pertanyaan yang di isi sendiri oleh responden yang datang berkunjung Di wilayah kerja Desa Cinta Rakyat. Kemudian responden terlebih dahulu menandatangani surat persetujuan menjadi responden lalu menjawab semua pertanyaan pada lembar kuesioner. Selanjutnya kuesioner dikumpulkan kembali untuk dilakukan pengelolaan data. Data yang dikumpul, diolah dengan cara manual dengan langkah - langkah sebagai berikut (Notoadmojo 2010):

1. Editing (Penyuntingan Data)

Yaitu Hasil wawancara atau angket yang diperoleh atau dikumpulkan melalui kuesioner perlu disuting (edit) terlebih dahulu. Kalau ternyata masih ada data atau informasi yang tidak lengkap, dan tidak mungkin dilakukan wawancara ulang, maka kuesioner tersebut di keluarkan.

2. Coding (Membuat lembaran kode)

Yaitu instrumen berupa kolom-kolom untuk merekam data secara manual. Lembaran atau kartu kode berisi nomor responden, dan nomor-nomor pertanyaan.

3. Memasukkan data

Yaitu mengisi kolom-kolom atau kotak-kotak lembar kode atau kartu kode sesuai dengan jawaban masing-masing pertanyaan.

4. Tabulasi

Yakni membuat tabel-tabel data, sesuai dengan tujuan penelitian atau yang diinginkan oleh peneliti.

Hasil analisa data akan dilakukan terhadap gambaran pengetahuan berdasarkan pada jawaban responden dari semua pertanyaan, pengetahuan yang di berikan berjumlah 20 soal. Defenisi operasional adalah uraian tentang batasan variable yang dimaksud, atau tentang apa yang diukur oleh variabel yang bersangkutan (Notoadmodjo, 2010).

\begin{tabular}{|c|c|c|c|c|}
\hline Variabel & $\begin{array}{l}\text { Pengertian } \\
\end{array}$ & Alat Ukur & Hasil & Skala \\
\hline Pengetahuan & $\begin{array}{l}\text { Hasil "tahu" dan terjadi setelah orang } \\
\text { melakukan penginderaan terhadap suatu } \\
\text { objek tertentu (Notoatmodjo, 2007) }\end{array}$ & Kuesioner & $\begin{array}{l}\text { a. Baik : } 80 \%-100 \% \\
\text { b. Cukup : } 55 \%-75 \% \\
\text { c. Kurang : }<55 \%\end{array}$ & Ordinal \\
\hline Pendidikan & $\begin{array}{l}\text { Suatu proses yang berarti dalam } \\
\text { pendidikan sehingga terjadi proses } \\
\text { pertumbuhan, perkembangan kearah } \\
\text { yang lebih dewasa dan lebih baik } \\
\text { (Notoatmodjo, 2007) }\end{array}$ & Kuesioner & $\begin{array}{l}\text { a. SD } \\
\text { b. SMP } \\
\text { c. SMA } \\
\text { d. PT }\end{array}$ & Ordinal \\
\hline Paritas & $\begin{array}{l}\text { Banyaknya kelahiran hidup yang } \\
\text { dipunyai oleh seorang wanita. } \\
\text { (Notoatmodjo, 2010) }\end{array}$ & Kuesioner & $\begin{array}{l}\text { a. Primipara (1) } \\
\text { b. Skundipara (2) } \\
\text { c. Multipara (3-5) } \\
\text { d. Grandemultipara (>5) }\end{array}$ & Ordinal \\
\hline
\end{tabular}




\begin{tabular}{|c|c|c|c|c|}
\hline $\begin{array}{l}\text { Sumber } \\
\text { Informasi }\end{array}$ & $\begin{array}{l}\text { Sumber informasi yang menjadi } \\
\text { perantara dalam menyampaikan } \\
\text { informasi (Notoatmodjo, 2007) }\end{array}$ & Kuesioner & $\begin{array}{l}\text { a. Tenaga kesehatan (dokter, } \\
\text { bidan, perawat) } \\
\text { b. Media massa (media cetak, } \\
\text { media elektronik) } \\
\text { c. Keluarga/teman }\end{array}$ & Nominal \\
\hline
\end{tabular}

\section{Aspek Pengukuran}

Aspek pengukuran dilakukan terhadap gambaran pengetahuan pada jawaban responden dari semua pertanyaan pengetahuan yang di berikan dengan jenis pertanyaan tertutup. Jumlah soal pertanyaan pengetahuan sebanyak 20 pertanyaan. Skor minimum adalah 0 dalam arti untuk jawaban 1 pertanyaan yang salah adalah 0. Skor maksimum adalah 1 dalam arti untuk skor jawaban terhadap 1 pertanyaan yang benar adalah 1.

Menjumlahkan skor yang di dapat dan di buat persentase dengan menggunakan rumus :

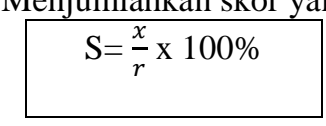

Keterangan :

S : Skor

$\mathrm{x}:$ Jawaban yang benar nilai 1

$\mathrm{r}$ : Jumlah soal

Sehingga dapat dikategorikan tingkat pengetahuan responden sebagai berikut:

1. Baik, apabila responden mendapat skor $75 \%-100 \%$ dengan jawaban yang benar $15-20$ pertanyaan.

2. Cukup, apabila responden mendapat skor $40 \%-70 \%$ dengan jawaban yang benar $8-14$ pertanyaan.

3. Kurang, apabila responden mendapat skor $0-35 \%$ dengan jawaban yang benar $0-7$ pertanyaan (Arikunto, 2006).

\section{RESULTS AND ANALYSIS}

\subsection{Hasil}

Dari hasil penelitian yang dilakukan yang berjudul "Gambaran Pengetahuan Ibu Tentang Pentingnya IMD Pada Bayi Baru Lahir di Di Wilayah Kerja Di Desa Cinta Rakyat" yang berjumlah 30 responden diperoleh hasil dan disajikan dalam tabel distribusi sebagai berikut:

\section{Pengetahuan}

Tabel 1. Distribusi Gambaran Pengetahuan Ibu Tentang Penting nya IMD Pada Bayi Baru Lahir Di Wilayah Kerja Di Desa Cinta Rakyat

\begin{tabular}{cccc}
\hline No & Tingkat Pengetahuan & F & \% \\
\hline 1 & Baik & 6 & 20 \\
\hline 2 & Cukup & 14 & 46,67 \\
\hline 3 & Kurang & 10 & 33,33 \\
\hline & Jumlah & $\mathbf{3 0}$ & $\mathbf{1 0 0}$ \\
\hline
\end{tabular}

Berdasarkan tabel diatas dapat dilihat bahwa mayoritas pengetahuan ibu tentang penting nya IMD pada bayi Baru lahir mayoritas Cukup sebanyak 14 responden (46,67\%) dan kelompok pengetahuan minoritas adalah baik sebanyak 6 responden (20\%).

\section{Berdasarkan Pendidikan}

Tabel 2. Distribusi Gambaran Pengetahuan Ibu Hamil Tentang Penting nya IMD Pada Bayi Baru Lahir Di Desa Cinta Rakyat

\begin{tabular}{|c|c|c|c|c|c|c|c|c|c|}
\hline \multirow{3}{*}{ No } & \multirow{3}{*}{ Pendidikan } & \multicolumn{6}{|c|}{ Pengetahuan } & \multirow{2}{*}{\multicolumn{2}{|c|}{ Total }} \\
\hline & & \multicolumn{2}{|c|}{ Baik } & \multicolumn{2}{|c|}{ Cukup } & \multicolumn{2}{|c|}{ Kurang } & & \\
\hline & & $\mathbf{F}$ & $\%$ & $\mathbf{F}$ & $\%$ & $\mathbf{F}$ & $\%$ & $\mathbf{F}$ & $\%$ \\
\hline 1 & $\mathrm{SD}$ & - & - & 1 & 3,33 & 3 & 10 & 4 & 13,33 \\
\hline 2 & SMP & - & - & 2 & 6,67 & - & - & 2 & 6,67 \\
\hline 3 & SMA & 2 & 10 & 8 & 26,67 & 7 & 23,33 & 17 & 56,67 \\
\hline 4 & Perguruan Tinggi & 4 & 13,33 & 3 & 10 & - & - & 7 & 23,33 \\
\hline & Jumlah & 6 & 20 & 14 & 46,67 & 10 & 33,33 & 30 & 100 \\
\hline
\end{tabular}

Berdasarkan tabel 2 diatas dapat dilihat bahwa mayoritas responden ibu berpengetahuan cukup dari pendidikan SMA sebanyak 8 responden $(26,67 \%)$ dan kelompok minoritas berpengetahuan cukup dari pendidikan SD adalah sebanyak 1 responden $(3,33 \%)$. 


\section{Bedasarkan Paritas}

Tabel 3. Distribusi Gambaran Pengetahuan Ibu Tentang Tentang Penting nya IMD Pada Bayi Baru Lahir Di

Desa Cinta Rakyat

\begin{tabular}{|c|c|c|c|c|c|c|c|c|c|}
\hline \multirow{3}{*}{ No } & \multirow{3}{*}{ Paritas } & \multicolumn{6}{|c|}{ Pengetahuan } & \multirow{2}{*}{\multicolumn{2}{|c|}{ Total }} \\
\hline & & \multicolumn{2}{|c|}{ Baik } & \multicolumn{2}{|c|}{ Cukup } & \multicolumn{2}{|c|}{ Kurang } & & \\
\hline & & $\mathbf{F}$ & $\%$ & $\mathbf{F}$ & $\%$ & $\mathbf{F}$ & $\%$ & $\mathbf{F}$ & $\%$ \\
\hline 1 & Primipara & 2 & 6,67 & 3 & 10 & 2 & 6,67 & 7 & 23,33 \\
\hline 2 & Skundipara & 2 & 6,67 & 4 & 13,33 & 3 & 10 & 9 & 30 \\
\hline 3 & Multipara & 1 & 3,33 & 3 & 10 & 2 & 6,67 & 6 & 20 \\
\hline 4 & Grandemultipara & 1 & 3,33 & 4 & 13,33 & 3 & 10 & 8 & 26,67 \\
\hline & Jumlah & 6 & 20 & 14 & 46,67 & 10 & 33,33 & 30 & 100 \\
\hline
\end{tabular}

Berdasarkan tabel 3 diatas dapat dilihat bahwa mayoritas ibu dengan paritas yang berpengetahuan cukup dari kategori skundipara dan grandemultipara masing-masing sebanyak 4 responden $(13,33 \%)$ dan kelompok minoritas pengetahuan baik pada multipara dan grandemultipara masing-masing sebanyak 1 responden $(3,33 \%)$.

\section{Berdasarkan Sumber Informasi}

Tabel 4. Distribusi Gambaran Pengetahuan Ibu Tentang Tentang Penting nya IMD Pada Bayi Baru Lahir Di Desa Cinta Rakyat

\begin{tabular}{|c|c|c|c|c|c|c|c|c|c|}
\hline \multirow{3}{*}{ No } & \multirow{3}{*}{ Sumber Informasi } & \multicolumn{6}{|c|}{ Pengetahuan } & \multirow{2}{*}{\multicolumn{2}{|c|}{ Total }} \\
\hline & & \multicolumn{2}{|c|}{ Baik } & \multicolumn{2}{|c|}{ Cukup } & \multicolumn{2}{|c|}{ Kurang } & & \\
\hline & & $\mathbf{F}$ & $\%$ & $\mathbf{F}$ & $\%$ & $\mathbf{F}$ & $\%$ & $\mathbf{F}$ & $\%$ \\
\hline 1 & Petugas Kesehatan & 2 & 6,67 & 7 & 23,33 & 2 & 6,67 & 12 & 40 \\
\hline 2 & Keluarga & 2 & 6,67 & 6 & 30 & 2 & 6,67 & 10 & 33,33 \\
\hline 3 & Media Masa & 2 & 6,67 & 2 & 6,67 & 5 & 16,67 & 8 & 26,67 \\
\hline & Jumlah & 5 & 16,67 & 15 & 50 & 9 & 30 & 30 & 100 \\
\hline
\end{tabular}

Berdasarkan tabel 4 diatas dapat dilihat bahwa pengetahuan ibu berdasarkan sumber informasi mayoritas berpengetahuan cukup pada ibu yang mendapat sumber informasi dari petugas kesehatan sebanyak 7 responden $(23,33 \%)$, dan minoritas berpengetahuan baik pada ibu yang mendapat sumber informasi dari media massa sebanyak 2 responden.

\subsection{Pembahasan Pengetahuan}

Berdasarkan hasil penelitian pada tabel 1 dapat dilihat bahwa mayoritas gambaran pengetahuan ibu tentang IMD adalah cukup sebanyak 14 responden $(46,67 \%)$ dan kelompok pengetahuan minoritas adalah baik sebanyak 6 responden $(20 \%)$.

Menurut (Notoatmodjo, 2010) Pengetahuan merupakan hasil tahu dari manusia, yang sekedar menjawab pertanyaan "What", misalnya pada air, pada manusia, apa alam dan sebagainya. Sedang ilmu (Science) bukan sekedar menjawab "What", melainkan akan menjawab pertanyaan "Why” dan "Who", misalnya mengapa air mendidih bila di panaskan, mengapa bumi berputar, mengapa manusia bernafas dan sebagainya. Pengetahuan hanya dapat menjawab pertanyaan apa sesuatu itu. Perlu di bedakan di sini antara pengetahuan dan keyakinan, walaupun kedua nya mempunyai hubungan yang erat (Notoatmodjo, 2010). Dari data diatas peneliti menarik kesimpulan bahwa gambaran pengetahuan ibu tentang IMD tentang masih rendah.

\section{Pendidikan}

Berdasarkan hasil penelitian tabel 2 diatas dapat dilihat bahwa mayoritas ibu berpengetahuan cukup dari pendidikan SMA sebanyak 8 responden $(26,67 \%)$ dan kelompok minoritas berpengetahuan cukup dari pendidikan SD adalah sebanyak 1 responden $(3,33 \%)$.

Menurut (Notoatmodjo, 2007) konsep dasar pendidikan adalah suatu proses belajar yang berarti di dalam pendidikan itu terjadi proses pertumbuhan, perkembangan, atau perubahan kearah lebih dewasa, lebih baik dan lebih matang pada diri individu, kelompok atau masyarakat dari yang tidak tahu menjadi tahu dan dari tidak mampu menjadi mampu dan sebagainya.

Dari data di atas peneliti menarik kesimpulan bahwa gambaran pendidikan seseorang mempengaruhi tingkat pengetahuan di mana semakin tinggi gambaran pendidikan seseorang maka makin mudah menerima sumber informasi sehingga banyak pula pengetahuan yang di peroleh. Ibu yang berpendidikan tinggi akan lebih baik dibandingkan dengan ibu yang berpendidikan rendah dalam pengetahuan nya teantang inisiasi menyusui dini.

\section{Paritas}

Berdasarkan hasil penelitian pada tabel 3 diatas dapat dilihat bahwa mayoritas ibu dengan paritas yang berpengetahuan cukup dari kategori skundipara dan grandemultipara masing-masing sebanyak 4 
responden $(13,33 \%)$ dan kelompok minoritas pengetahuan baik pada multipara dan grandemultipara masingmasing sebanyak 1 responden (3,33). Menurut (Notoatmodjo, 2007) Paritas adalah jumlah anak yang dilahirkan oleh seorang ibu baik yang hidup maupun yang mati dimana bayi telah Viable. Menurut peneliti paritas sangat mempengaruhi gambaran pengetahuan ibu tentang inisiasi menyusu dini karena semakin banyak anak yang dilahirkan maka semakin banyak pengalaman dan ini akan meningkatkan pengetahuan ibu tentang inisiasi menyusu dini dan cara menyusui yang baik dan benar.

\section{Sumber Informasi}

Berdasarkan tabel 4 diatas dapat dilihat bahwa ibu berdasarkan sumber informasi mayoritas yang berpengetahuan cukup pada ibu yang mendapat sumber informasi dari petugas kesehatan sebanyak 7 responden $(23,33 \%)$, dan minoritas berpengetahuan baik pada ibu yang mendapat sumber infor masi dari media massa sebanyak 2 responden $(6,67)$.

Menurut (Notoatmodjo, 2007) bahwa informasi yang diperoleh baik dari pendidikan formal maupun non formal dapat memberikan pengaruh sehingga menghasilkan perubahan atau peningkatan pengetahuan. Dengan berkembangnya pendidikan dan teknologi muncullah bermacam-macam media elektronik dan media massa yang dapat mempengaruhi pengetahuan masyarakat tentang berita terbaru.

Menurut peneliti sumber informasi sangat mempengaruhi pengetahuan dan dalam hal ini peneliti menarik kesimpulan bahwa hasil yang diperoleh dilapangan tidak sesuai dengan teori yang ada karena ibu hamil mencari sumber informasi dari orang-orang disekelilingnya dalam penetahuan mengenai inisiasi menyusu dini.

Semakin tinggi pendidikan seseorang, semakin mudah menerima informasi, sehingga semakin banyak pula pengetahuan yang dimiliki, sebaliknya pendidikan yang kurang akan menghambat perkembangan sikap seseorang terhadap nilai yang di perkenalkan (Maryani, 2009). Dari hasil penelitian yang di dapat oleh Rahunia sebelumnya, ternyata masih kurangnya pengetahuan ibu tentang pentingnya Inisiasi Menyusui Dini Pada Bayi baru lahir yang mengakibatkan angka kematian pada bayi sangat tinggi di Indonesia. Salah satu untuk meningkatkan IMD yaitu di harapkan kepada Petugas kesehatan memberikan penyuluhan kepada ibu - ibu hamil agar memberikan pengetahuan tentang pentingnya IMD dan supaya termotivasi juga untuk melakukan IMD segera setelah bayi lahir.

Penyebab dari permasalahan tersebut adalah faktor kurangnya pengetahuan, akan pentingnya ASI untuk kesehatan anak, pelayanan kesehatan dan petugas kesehatan yang belum sepenuhnya mendukung program peningkatan pengunaan ASI, gencarnya promosi susu formula dan Ibu yang bekerja (Roesli, 2008). Masih banyak juga Ibu yang mempunyai pengetahuan kurang baik tentang inisiasi menyusui dini pada bayi baru lahir kemungkinan disebabkan karena kurangnya kesadaran ibu akan pentingnya inisiasi menyusui dini bagi pertumbuhan dan perkembangan anak. Selain faktor kesadaran ibu tentang kesehatan, faktor lainya yang kemungkinan berpengaruh terhadap kurang baiknya pengetahuan Ibu tentang Inisiasi menyusu dini pada bayi baru lahir adalah kurangnya akses informasi dari kesehatan dalam memberikan pendidikan kesehatan (Roesli U, 2012).

Menurut (Notoatmojo, 2007) bahwa pengetahuan adalah berbagai gejala yang ditemui dan diperoleh manusia melalui pengamatan indera. Pengetahuan muncul ketika seseorang menggunakan indera atau akal budinya untuk mengenali benda atau kejadian tertentu yang belum pernah dilihat atau dirasakan sebelumnya. Menurut asumsi peneliti dari hasil tersebut menunjukkan bahwa pengetahuan ibu hamil mempengaruhi tentang IMD. Jika Semakin baik pengetahuan ibu hamil, maka semakin termotivasi pula melakukan Inisiasi menyusui dini segera setelah bayi lahir, sehingga angka kematian bayi pun akan semakin menurun dan keberhasilan ASI aksklusif semakin baik.

\section{CONCLUSION}

Dari hasil penelitian mengenai Gambaran Pengetahuan Ibu tentang inisiasi menyusu dini pada bayi baru lahir Di Desa Cinta Rakyat, maka diambil kesimpulan sebagai berikut:

1. Dari 30 responden mayoritas pengetahuan ibu tentang IMD pada bayi baru lahir adalah cukup sebanyak 14 responden $(46,67 \%)$ dan kelompok pengetahuan minoritas adalah baik sebanyak 6 responden $(20 \%)$.

2. Dari 30 responden mayoritas ibu berpengetahuan cukup dari pendidikan SMA sebanyak 8 responden $(26,67 \%)$ dan kelompok minoritas berpengetahuan cukup dari pendidikan SMA adalah sebanyak 1 responden $(3,33 \%)$.

3. Dari 30 responden mayoritas berpengetahuan cukup dari kategori skundipara dan grandemultipara masing-masing sebanyak 4 responden $(13,33 \%)$, dan kelompok minoritas pengetahuan baik pada multipara dan grande multipara masing-masing sebanyak 1 responden $(3,33 \%)$.

4. Dari 30 responden yang diteliti dapat dilihat bahwa berdasarkan sumber informasi mayoritas berpengetahuan cukup pada ibu tentang IMD yang mendapat sumber informasi dari petugas kesehatan 
sebanyak 7 responden $(23,33 \%)$, dan minoritas berpengetahuan baik pada ibu yang mendapat sumber informasi dari media masa sebanyak 2 responden $(6,67 \%)$.

\section{REFERENCES}

Azwar, S. (2016). Metode Penelitian. Yogyakarta: Pustaka Pelajar.

Ambarwati Retna Eny dan Ulandari Diah. 2009. Asuhan Kebidanan Nifas. Yokyakarta: Mitra Cendikia Press.

Hidayat, A. A. (2012). Riset Keperawatan dan Teknik Penulisan Ilmiah. Jakarta: Salemba Medika.

http://inanooryati.inisiasi menyusui dini, 5 september 2009.

http://Kesehatan Ibu dan anak wordpress.com. kamis, 12 november 2009.

Maryunani, Anik. 2009. Buku Asuhan Pada Ibu dalam Masa Nifas. Jakarta: Trans Info Media.

Notoadmodjo, S. 2007. Buku Penelitian Kesehatan. Jakarta: Rineka cipta.

Notoatmodjo, Soekidjo. 2010. Metodologi Penelitian Kesehatan. Jakarta: Rineka Cipta.

Proverawati, Atikah., Rahmawati. Eni. 2010. Kapita Selekta ASI dan Menyusui. Yokyakarta: Nuha Medika.

Riksani Ria. 2010. Buku Keajaibaan ASI. Jakarta: Dunia Sehat.

Suherni, dkk. 2009. Perawatan Masa Nifas. Yogyakarta: Fitramaya.

Siswono. 2003. Kematian Ibu Indonesia tertinggi di ASEAN. Http://one.indoskripsi.Com.

Sutiyah. 2010. http://Keluarga/anak/40-anak/99-Inisiasi-menyusu.

Waryana. 2010. Buku Gizi Reproduksi. Cetakan Pertama. Yogjakarta: Pustaka Rihama.

Williams. 2007. http://hipotermia.com.servei-demografi.

www.infokesehatan.com/pdf/Inisiasi menyusui dini.htmlwww.artikelkebidanan.com

Yeyeh, ai rukiyah., Yuliati, lia. 2010. Asuhan Neonatus Bayi Dan Anak Balita. Jakarta: Trans Info Media.

\section{BIOGRAPHIES OF AUTHORS}

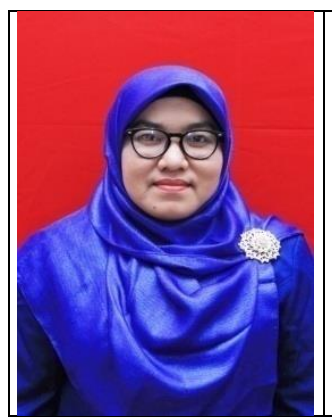

Mira Indrayani, Gelar D-III diperoleh dari Akademi Kebidanan Imelda Medan, Jurusan Kebidanan pada tahun 2007. Gelar D4 diperoleh dari Poltekes Kemenkes RI Medan, Jurusan Bidan Pendidik Tahun 2009. Magister Kesehatan diperoleh dari Universitas Sumatera Utara, Jurusan Kesehatan Reproduksi pada tahun 2018. Saat ini aktif sebagai dosen tetap di Prodi S1 Kebidanan Universitas Imelda Medan dan menjabat sebagai wakil Rektor 3. 